\title{
Solidification Behavior and Microstructural Evolution of Near-Eutectic Zn-Al Alloys under Intensive Shear
}

\begin{abstract}
S. JI and Z. FAN
The effect of intensive shear on the solidification behavior and microstructural evolution of binary $\mathrm{Zn}-\mathrm{Al}$ alloys is presented at hypoeutectic, eutectic, and hypereutectic compositions. It is found that the intensive shear, applied on the eutectic melt prior to solidification at a temperature above but close the eutectic temperature, can significantly reduce the size of eutectic cells, but the solidified microstructure still remains the lamellar morphology. For applying intensive shear on the melt during solidification, the nucleation occurs at temperatures very close to the equilibrium condition and requires very small undercooling for both the primary solidification and the eutectic solidification. The intensive shear can significantly alter the microstructural morphology. In contrast to the dendritic morphology formed in the conventional solidification, the primary Al-rich phase in hypoeutectic Zn-Al alloy and the primary Zn-rich phase in hypereutectic $\mathrm{Zn}-\mathrm{Al}$ alloy under intensive shear exhibit fine and spherical particles, respectively. The lamellae morphology of Zn-rich phase and Al-rich phase formed in the conventional eutectic solidification exhibit fine and spherical particles. The increase of intensity of shear promotes the independence of solid Zn-rich particles and Al-rich particles during the eutectic solidification, resulting in the uniform and separate distribution of two solid particles in the matrix. It is speculated that the high intensity of shear can result in the independent nucleation of individual eutectic phase throughout the whole melt, and the separate growth of solid phases in the subsequent solidification.
\end{abstract}

DOI: $10.1007 / \mathrm{s} 11661-008-9713-0$

(C) The Minerals, Metals \& Materials Society and ASM International 2008

\section{INTRODUCTION}

THE effect of shear-induced convection on the solidification behavior and microstructural evolution of eutectic alloys has been a promising subject of many studies in the last several decades. In the 1960s, on the basis of Jackson and Hunt's model, ${ }^{[1]}$ Verhoeven and Homer $^{[2]}$ reported that the convective flow produced little effect on eutectic growth in the eutectic solidification. However, from the mid 1970s, the shear-induced convection was found to result in modifications of eutectic microstructure during solidification. Larson $^{[3]}$ reported that the increased convection causes a significant reduction of interlamellar spacing $\lambda$ for $\mathrm{Mn}-\mathrm{Bi}$ fibrous eutectics. Conversely, Quenisset et al. ${ }^{[4,5]}$ found that the vigorous convection can cause the eutectic spacing to increase in directional solidification of $\mathrm{Pb}-\mathrm{Sn}$ and $\mathrm{Cd}-\mathrm{Zn}$ alloys. The experimental results carried by Jin et al. ${ }^{[6]}$ from the solidification of $\mathrm{Al}-\mathrm{Cu}$ eutectics with electromagnetic stirring of the melt indicated that the eutectic interlamellar spacing $\lambda$ increases if the Peclet number $\mathrm{Pe}$ is $>1$, whereas $\lambda$ changes little for $\mathrm{Pe}<1$. Li et $a .^{[7]}$ investigated the effect of convection on upward directional solidification of $\mathrm{Pb}-\mathrm{Sn}$ alloy. They found that

S. JI, SCM Manager, is with Arcadia Products plc, Surrey RH1 5DY, United Kingdom. Contact e-mail: shouxun.ji@gmail.com Z. FAN, Professor, is with the Brunel Centre for Advanced Solidification Technology (BCAST), Brunel University, Uxbridge, UB8 3PH, United Kingdom.

Manuscript submitted February 28, 2008.

Article published online November 18, 2008 the average of interlamellar spacing becomes smaller with the increase of solid fraction during solidification. On the other hand, Apaydin ${ }^{[8]}$ observed that the mechanical stirring during solidification of Al-Si eutectics brings uncommon eutectic microstructures, in which eutectic phases separate from each other and grow in an uncoupled manner. Chen and Davis ${ }^{[9,10]}$ also found that the fluid motions during the eutectic solidification perturb the solute distribution, and therefore modify the crystal growth direction. Apparently, the aforementioned theoretical understandings and experimental observations are not quite consistent and some conclusions are conflicting. Therefore, further work is necessary to consolidate the experimental observation and to extend the understanding of the solidification under the forced convection.

The shear-induced convection can be produced at different approaches, including by linear flow over a chill, rotation of the crucible and internal disk or cylinder at various angles to the heat flow vector, and by electromagnetic forces. ${ }^{[11]}$ However, the shear produced by existing techniques seems relatively weak, although there was no special value available in literature. The publications about the solidification behavior, the effect of intensive shear on the phase formation, and morphology of eutectic phases are still absent for alloys at compositions close to the eutectic point (denoted as near-eutectic alloys). Therefore, this article aims to study the solidification behavior and microstructural evolution of near-eutectic $\mathrm{Zn}-\mathrm{Al}$ alloys under intensive 
shear created by a closely intermeshing, self-wiping, and corotating twin-screw extruder. ${ }^{[12]}$ Three near-eutectic alloys at hypoeutectic, eutectic, and hypereutectic compositions are chosen for the evolution of primary phase and eutectic phases under the intensive forced convection. The nucleation temperatures of the near-eutectic $\mathrm{Zn}-\mathrm{Al}$ alloys are measured under shear and compared with the equilibrium phase diagram. The discussions are given for the nucleation and growth of solid phases during the eutectic solidification under the intensive forced convection.

\section{EXPERIMENTAL}

Pure elemental raw materials Zn (99.95 wt pet purity) and Al (99.995 wt pct purity) were used to make Zn-Al alloy ingots containing 3 to $7 \mathrm{wt}$ pet Al. The raw materials were weighed to a specific alloy and melted in an electric-heated furnace within a graphite crucible. The crucible was heated up to $700{ }^{\circ} \mathrm{C}$ and then $\mathrm{Al}$ was melted, following adding $\mathrm{Zn}$ into the crucible while reducing the temperature of furnace. To complete melting and ensure solute homogenization, each alloy was held at $450{ }^{\circ} \mathrm{C}$ to $500{ }^{\circ} \mathrm{C}$ for 30 minutes before casting into a copper mold. Each alloy was analyzed by optical mass spectroscopy for determining the chemical composition. The composition was characterized by the average value of 12 burnings at 3 points on a cross section of a $\phi 40-\mathrm{mm}$ specially-made casting. One of these castings was metallographically examined in order to observe the resultant microstructures for confirming alloy homogeneity. The ingots were remelted in an electric-heated furnace to a temperature $50{ }^{\circ} \mathrm{C}$ above their liquidus and held for about 20 to 30 minutes before use.

A $\phi 16-m m$ twin-screw extruder was used to produce shear in this investigation. Figure 1 is a schematic illustration of a laboratory scale twin-screw extruder. It consists of a feeder, a barrel, and a pair of closely intermeshing, self-wiping, and corotating screws, an outlet valve, and a control unit. The screw has a specially designed profile to assist the achievement of high shear rate and high intensity of turbulence. The matched heating elements and cooling channels dispersed along the barrel ensure a uniform temperature distribution. The temperature of the sheared melt is measured by a separate thermocouple in direct contact with the melt near the end of the extruder (denoted as melt $\mathrm{T} / \mathrm{C}$ in Figure 1). The melt $\mathrm{T} / \mathrm{C}$ was calibrated regularly during experiments with an accuracy of $0.1{ }^{\circ} \mathrm{C}$. The fluid flow in the extruder is characterized by high shear rate, high intensity of turbulence, and cyclic variation of shear rate. ${ }^{[13]}$ The shear rate used in this article refers to that between the inner surface of barrel and the tip of screw flight and is calculated by equation $\dot{\gamma}=\pi \omega(D / \delta-2)$, where $\omega$ is the rotation speed of screw, $D$ the outer diameter of screw, and $\delta$ the gap between the tip of screw flight and the inner surface of barrel. The shear rate is used as a measure of the intensity of the forced convection, turbulence, and the flow instability of sheared materials in twin-screw extruder.

During experiments, the temperature control was achieved by controlling the barrel temperature with an accuracy of $1{ }^{\circ} \mathrm{C}$. The extruder was heated to a temperature above the liquidus of alloy and run at a given shear rate. The $\mathrm{Zn}-\mathrm{Al}$ melt was poured into the twin-screw extruder at a temperature $10{ }^{\circ} \mathrm{C}$ above its liquidus. The melt immediately experienced shear while passing through the gap between the screws and barrel. The melt was isothermally sheared for 30 to 45 seconds before being cooled continuously with a controlled cooling rate. When the sheared melt reached the sampling points, the melt temperature was recorded and the melt was immediately tapped into a cold-water tank for quenching. The samples were then examined

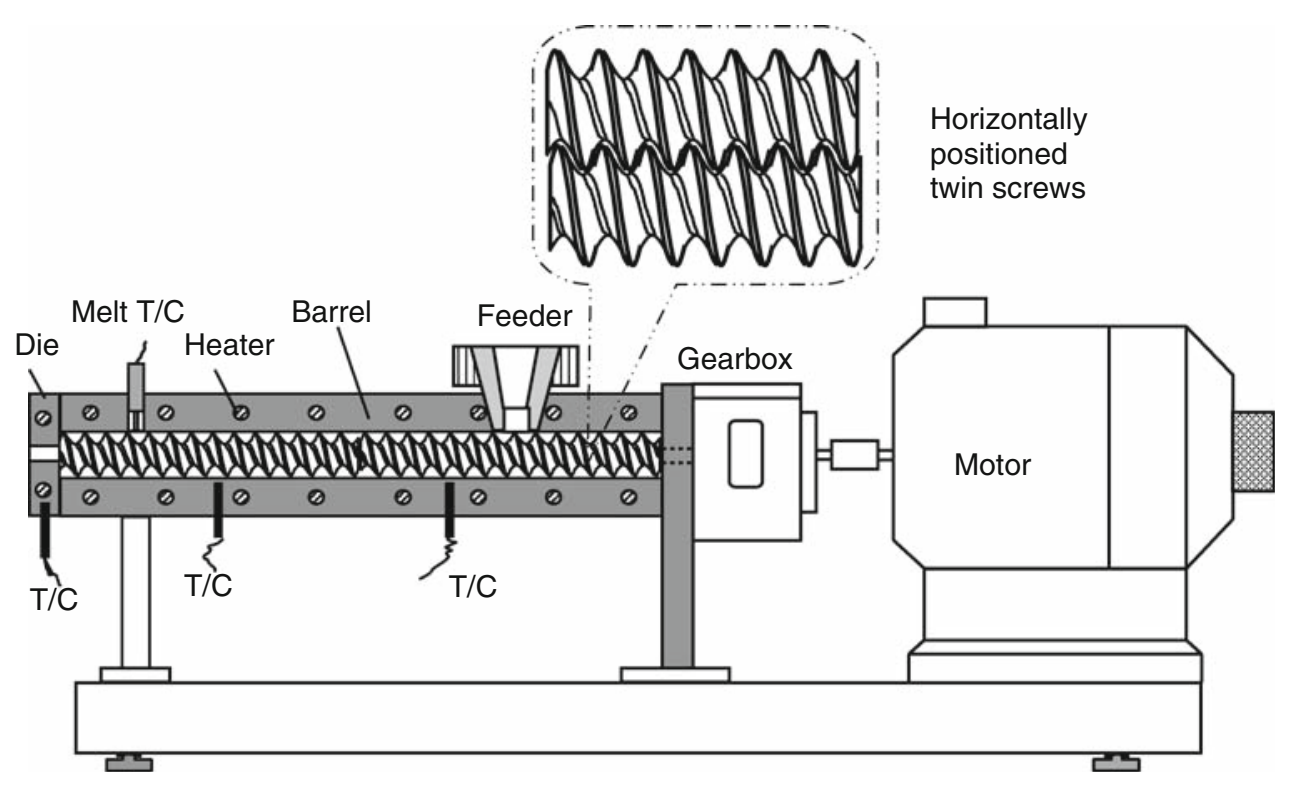

Fig. 1-Schematic diagram of twin-screw extruder used for producing intensively forced convection. 
individually by microscopy. The temperature where one kind of solid phase was observed in the water-quenched specimens was defined as nucleation temperature of primary phase. The temperature where two kinds of solid phases were observed in the water-quenched specimens was defined as nucleation temperature of eutectics.

The microstructure of each alloy was examined using a Zeiss optical microscopy (OM) with quantitative metallography and a JEOL JXA-840A scanning electron microscopy (SEM) (JEOL Ltd., Tokyo, Japan) equipped with an energy dispersive spectroscopy (EDS) facility. The specimens for OM and SEM were prepared by the standard technique of grinding with $\mathrm{SiC}$ abrasive paper and polishing with an $\mathrm{Al}_{3} \mathrm{O}_{2}$ suspension solution. At least 200 particles were measured and the average value was taken for particle size, volume fraction, and shape factor $(F)$ of the particles. The $F$ was calculated by $F=4 \pi A / P^{2}$, where $A$ and $P$ are the area and the peripheral length of the primary particles, respectively.

\section{RESULTS}

\section{A. Nucleation under Intensive Shear}

In order to determine the nucleation of solid phase under intensive shear, a series of cooling curves were recorded and a number of specimens were metallurgically examined for the intensively sheared $\mathrm{Zn}-\mathrm{Al}$ alloys. The solidification is deliberately described in two steps for convenience in explanation. The solidification of hypoeutectic or hypereutectic alloys to form one kind of solid phase is defined as the primary solidification. The solidification for eutectic reaction to form two kinds of solid phases is defined as the eutectic solidification. Figure 2 shows the typical cooling curve of $\mathrm{Zn}-5$ wt pct $\mathrm{Al}$ alloy under intensive shearing at $4082 \mathrm{~s}^{-1}$ and a cooling rate of extruder at $1^{\circ} \mathrm{C} / \mathrm{min}$. The solidification stabilized at $380.6^{\circ} \mathrm{C}$, by which the undercooling was

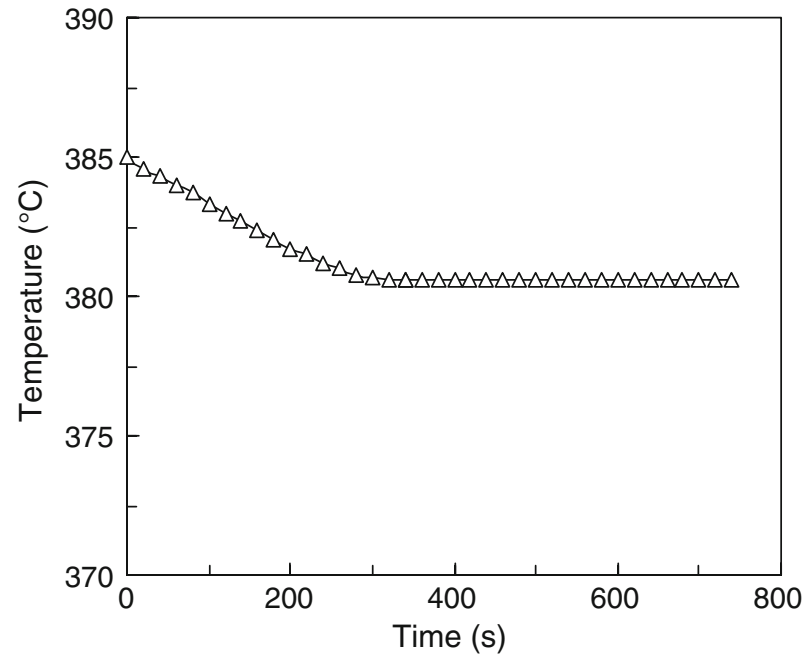

Fig. 2-Typical cooling curve of $\mathrm{Zn}-5$ wt pet $\mathrm{Al}$ alloy under continuous shearing at $4082 \mathrm{~s}^{-1}$ and a cooling rate of barrel at $1^{\circ} \mathrm{C} / \mathrm{min}$.
$0.4{ }^{\circ} \mathrm{C}$ in comparison to $381{ }^{\circ} \mathrm{C}$ at equilibrium phase diagram. ${ }^{[14]}$ No apparent recalescence was found in experimental conditions. The micrographically determined nucleation temperatures are shown graphically in Figure 3 for the near-eutectic $\mathrm{Zn}-\mathrm{Al}$ alloys continuously sheared at $4082 \mathrm{~s}^{-1}$ and cooled at $1{ }^{\circ} \mathrm{C} / \mathrm{min}$ from a liquid state. The solid lines are the equilibrium phase diagram reproduced from published literature. ${ }^{[14]}$

Figure 3 clearly shows that the nucleation temperatures of $\mathrm{Zn}-\mathrm{Al}$ alloys under intensive shear were very close to the temperature shown on equilibrium phase diagram. For hypoeutectic and hypereutectic $\mathrm{Zn}-\mathrm{Al}$ alloys the primary phase emerged within $0.5^{\circ} \mathrm{C}$ below the equilibrium liquidus temperature. Both Al-rich phase and Zn-rich phase were observed with similar behavior during the primary solidification. Figure 3 also shows the eutectic solidification temperature of various $\mathrm{Zn}-\mathrm{Al}$ alloys. The eutectic solidification occurred at $380.6{ }^{\circ} \mathrm{C}$ for $\mathrm{Zn}-5$ wt pct $\mathrm{Al}$ eutectic alloy, and $380.5^{\circ} \mathrm{C}$ for near-eutectic Zn-6.3 wt pet Al alloy and Zn-4.1 wt pet $\mathrm{Al}$ alloy. The repeatable results produced by the twinscrew extruder confirmed that the solidification under intensive shear requires small undercooling for the nucleation of both primary and eutectic phases. This implies that the solidification under intensive shear is close to equilibrium solidification.

\section{B. Microstructure of Eutectic Zn-Al Alloy Sheared Prior to Solidification}

Figure 4 shows the effect of intensive shear prior to solidification on the microstructure of $\mathrm{Zn}-5$ wt pet $\mathrm{Al}$ alloys. The melt was cast after intensive shearing at $385^{\circ} \mathrm{C}$. As a comparison, it also shows the microstructure of an identical alloy in the conventional solidification under an identical cooling condition. The micrographs showed that the lamellar microstructure was formed in the alloys solidified under the conven-

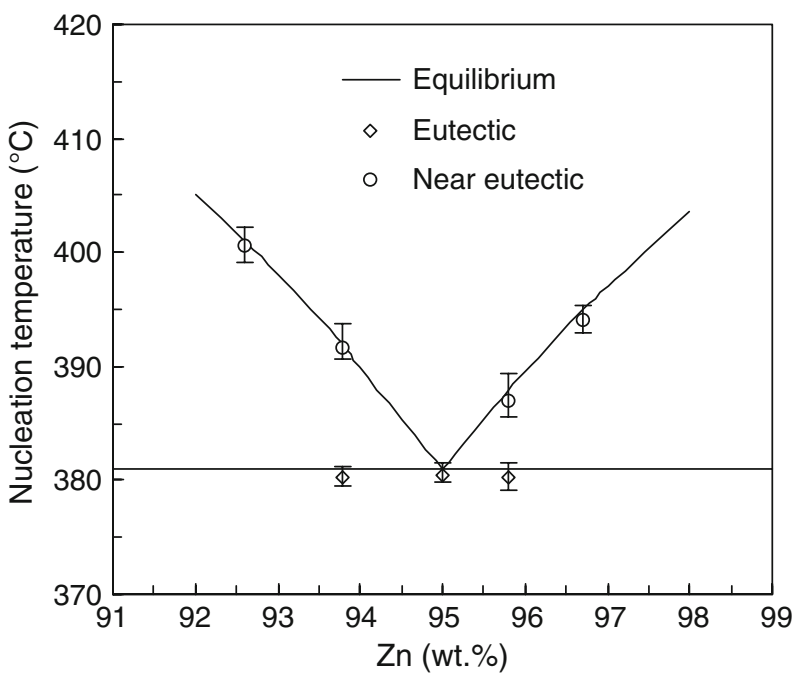

Fig. 3-Nucleation temperatures for eutectic and near-eutectic $\mathrm{Zn}-\mathrm{Al}$ alloys under intensive shearing with $4082 \mathrm{~s}^{-1}$ and continuous cooling at $1{ }^{\circ} \mathrm{C} / \mathrm{min}$ from $385^{\circ} \mathrm{C}$. Solid line is the equilibrium phase diagram taken from Ref. 14. 

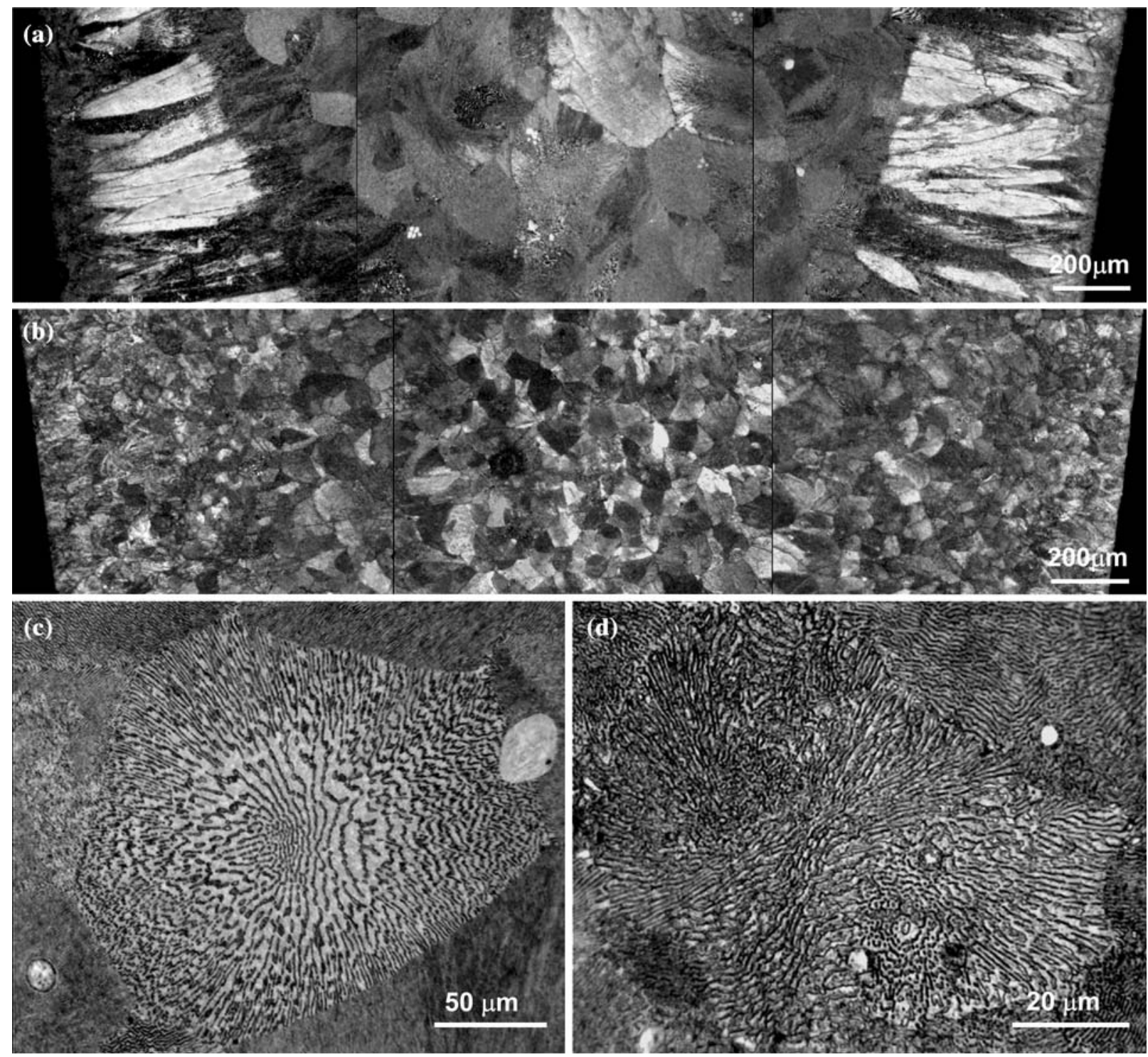

Fig. 4 - OM showing microstructure of Zn-5 wt pet Al alloy solidified at an identical condition: $(a)$ on cross section of V-type copper mold under conventional solidification from $385^{\circ} \mathrm{C},(b)$ on cross section of V-type copper mold after shearing at $385{ }^{\circ} \mathrm{C}$ with a shear rate of $4082 \mathrm{~s}^{-1}$ for $60 \mathrm{~s},(c)$ details of eutectic cell from (a), and (d) details of eutectic cell from (b).

tional casting (Figures 4(a) and (c)) and under intensive shear (Figures 4(b) and (d)). However, the microstructure of priory sheared $\mathrm{Zn}-5$ wt pct $\mathrm{Al}$ alloy exhibited the absence of columnar zone, smaller grain size, and finer interlamellar spacing. The interlamellar spacing was typically at $1 \mu \mathrm{m}$ and grain size at $90 \mu \mathrm{m}$. In contrast, the conventionally solidified $\mathrm{Zn}-5$ wt pet $\mathrm{Al}$ alloy in Figures 4(a) and (c) demonstrated nonuniformly distributed lamellae, larger interlamellar spacing of $6.25 \mu \mathrm{m}$ in the middle, and smaller interlamellar spacing of $1.75 \mu \mathrm{m}$ around the edge of the grain. The average grain size was $197 \mu \mathrm{m}$. The results revealed that the intensive shear at a temperature above but close to the liquidus can uniform and refine the microstructure by producing smaller grain size and uniformly distributed interlamellar spacing within the grain. However, the morphology still remains the conventional lamellar microstructure.

\section{Microstructure of Eutectic Zn-Al Alloy Solidified under Intensive Shear}

Figure 5 shows the microstructures of $\mathrm{Zn}-5$ wt pet Al alloy solidified at the initial stage after shearing at $4082 \mathrm{~s}^{-1}$ and cooling at $1{ }^{\circ} \mathrm{C} / \mathrm{min}$ from $385^{\circ} \mathrm{C}$. The micrographs revealed that the solidification occurred under intensive shear could significantly alter the morphology of the eutectic solidification. In contrast to the lamellar microstructure in the conventional solidification, the morphology of both Al-rich and Zn-rich eutectic phases exhibited spherical particles under intensive shear. The Al-rich particles and Zn-rich particles showed two kinds of arrangements, isolated particles and coupled particles. The isolated particles distributed randomly in the matrix. The coupled particles showed a cluster of several particles of one phase sticking on one, or several particles of the other phase. The solid fraction 

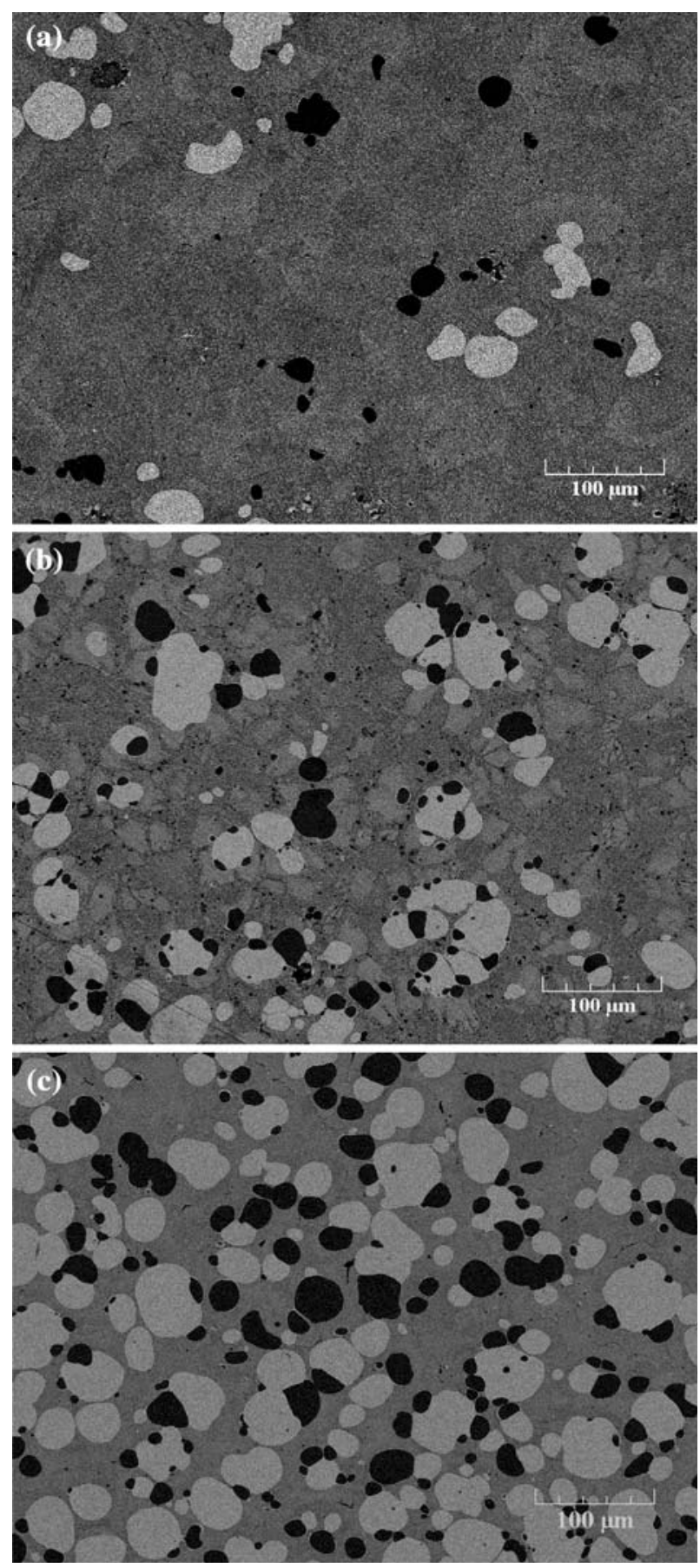

Fig. 5-Backscattered SEM micrographs showing water-quenched microstructures of $\mathrm{Zn}-5$ wt pct $\mathrm{Al}$ alloy at initial stage of eutectic solidification, the alloy was continuously sheared at $4082 \mathrm{~s}^{-1}$, cooled at $1{ }^{\circ} \mathrm{C} / \mathrm{min}$ from $385^{\circ} \mathrm{C}$ to $380.6^{\circ} \mathrm{C}$, and times after reaching $380.6^{\circ} \mathrm{C}$ : (a) $0 \mathrm{~s}$, (b) $60 \mathrm{~s}$, and (c) $120 \mathrm{~s}$ (white particles $=\mathrm{Zn}$ phase, and black particles $=\mathrm{Al}$ phase).

of both Al-rich and Zn-rich particles increased with prolonged shearing during the initial stage of the eutectic solidification. Figure 6 shows the mean particle size as a function of the solid fraction of $\mathrm{Zn}$-rich particles and Al-rich particles in $\mathrm{Zn}-5$ wt pet $\mathrm{Al}$ alloy sheared at $4082 \mathrm{~s}^{-1}$ and cooled at $1^{\circ} \mathrm{C} / \mathrm{min}$ from $385^{\circ} \mathrm{C}$. Clearly, the mean particle size demonstrated

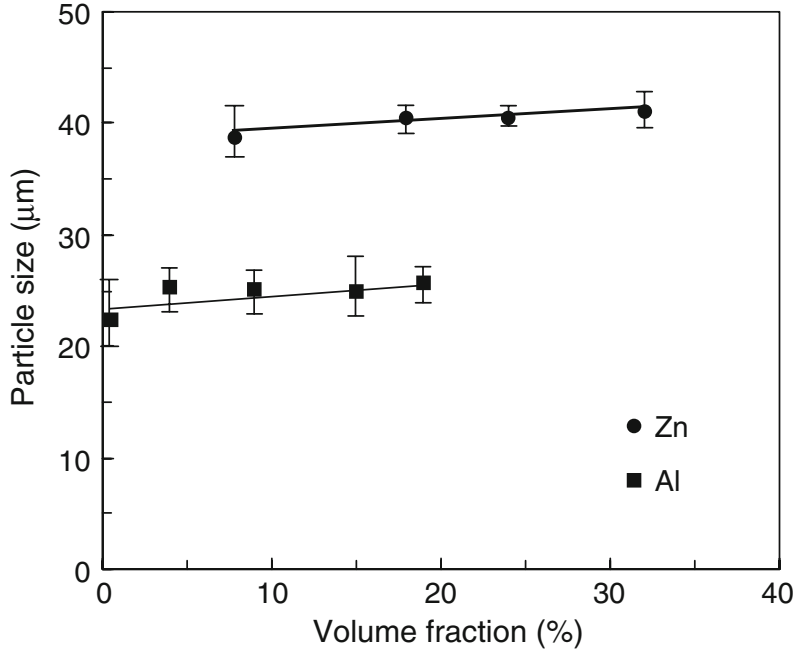

Fig. 6-Mean particle size as a function of volume fraction of solid phases in $\mathrm{Zn}-5$ wt pct $\mathrm{Al}$ alloy produced under shearing at $4082 \mathrm{~s}^{-1}$ and cooling at $1{ }^{\circ} \mathrm{C} / \mathrm{min}$ from $385^{\circ} \mathrm{C}$ to $380.6^{\circ} \mathrm{C}$, followed by water quenching.

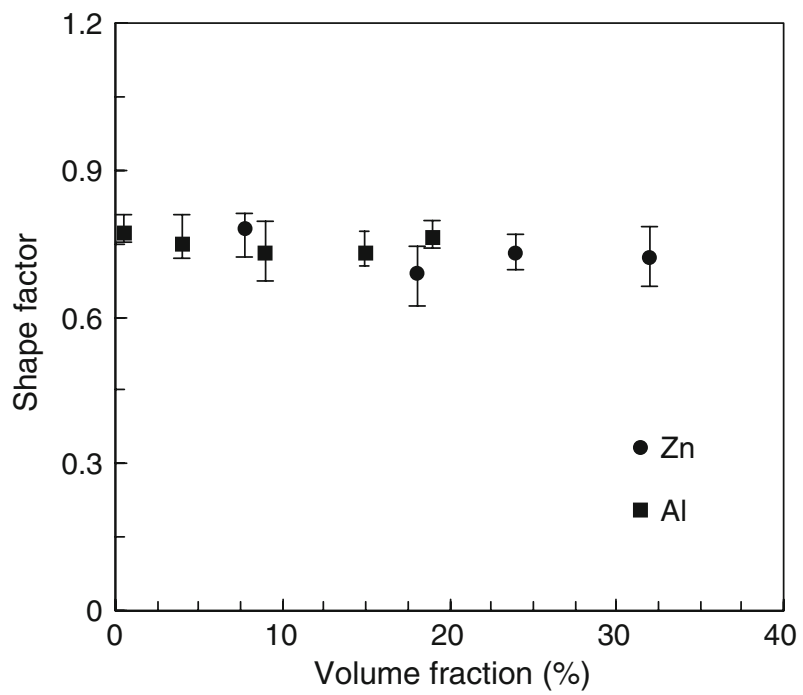

Fig. 7- Shape factor as a function of volume fraction of solid phases in $\mathrm{Zn}-5 \mathrm{wt}$ pct Al alloy produced under shearing at $4082 \mathrm{~s}^{-1}$ and cooling at $1{ }^{\circ} \mathrm{C} / \mathrm{min}$ from $385{ }^{\circ} \mathrm{C}$ to $380.6{ }^{\circ} \mathrm{C}$, followed by water quenching.

insignificant variation at different volume fractions of either Al-rich particles or Zn-rich particles, except that the slightly smaller Al-rich particles were found at the initial stage of solidification. The mean size of Al-rich particles remained at $25.5 \mu \mathrm{m}$, while $\mathrm{Zn}$-rich particles stabilized at $40.8 \mu \mathrm{m}$ in the experimental conditions. Similarly, the shape factors of Al-rich and Zn-rich phases, shown in Figure 7 as a function of the volume fraction of solid particles, were relatively consistent at the order of 0.75 .

Figure 8 shows the effect of shear rate on the microstructure of $\mathrm{Zn}-5$ wt pet Al alloy continuously sheared and cooled at $1{ }^{\circ} \mathrm{C} / \mathrm{min}$. The micrographs exhibited the spherical morphology of relatively larger 

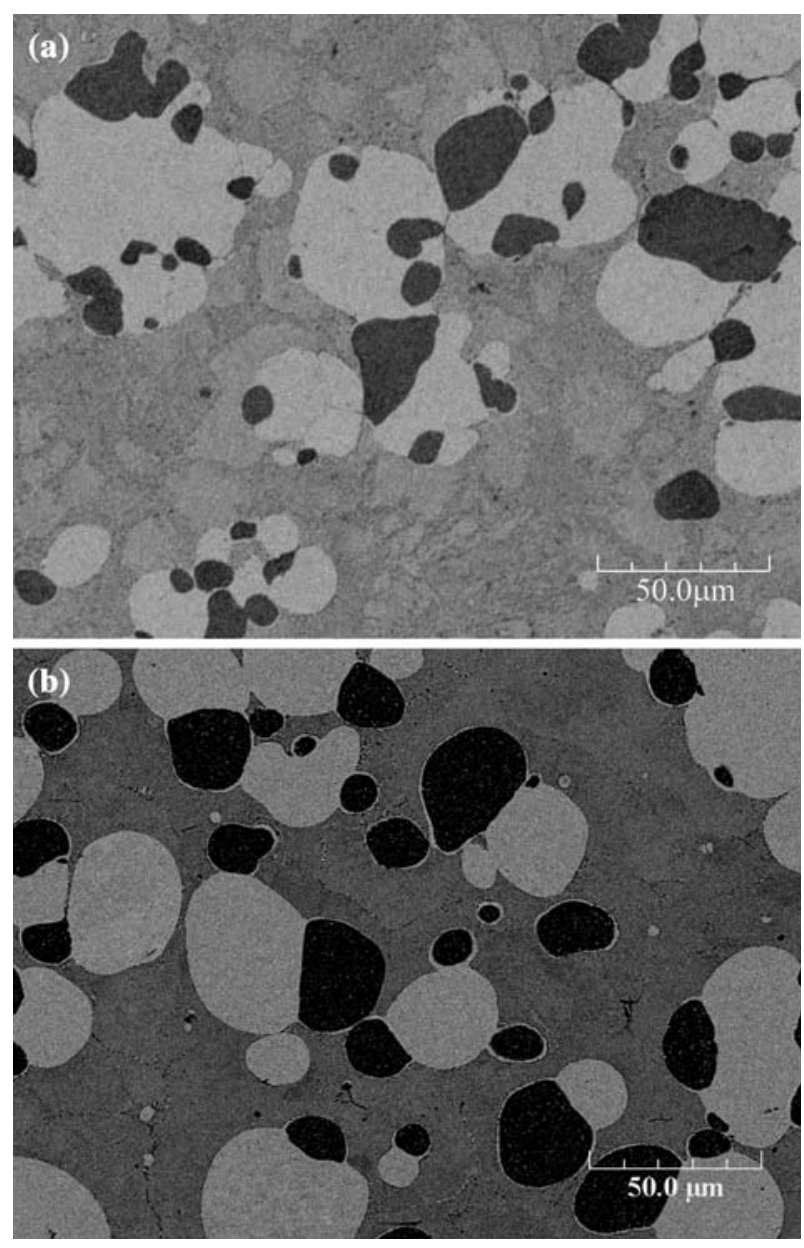

Fig. 8-Backscattered SEM micrographs showing the effect of shear rate on the microstructural morphology of $\mathrm{Zn}-5 \mathrm{wt}$ pet $\mathrm{Al}$ alloy produced by continuously cooling at $1{ }^{\circ} \mathrm{C} / \mathrm{min}$ from $385^{\circ} \mathrm{C}$ to $380.6^{\circ} \mathrm{C}$, followed by water quenching: (a) $1224 \mathrm{~s}^{-1}$ and (b) $4082 \mathrm{~s}^{-1}$ (white particles $=\mathrm{Zn}$ phase, and black particles $=\mathrm{Al}$ phase).

Zn-rich particles and relatively smaller Al-rich particles at 1224 and $4082 \mathrm{~s}^{-1}$. However, there were more Al-rich particles in the vicinity of one Zn-rich particle at lower shear rates. One Zn-rich particle was typically surrounded by 2 to $10 \mathrm{Al}$-rich particles at $1224 \mathrm{~s}^{-1}$ but only 1 to 3 Al-rich particles at $4082 \mathrm{~s}^{-1}$. Meanwhile, in comparison to the results produced in two shear rates, there were more isolated and spherical Al-rich and $\mathrm{Zn}$-rich particles distributed in the matrix at higher shear rates. The results implied that the increased independence of spherical particles could result from the higher intensity of shear during the eutectic solidification. The experiments also confirmed that the shear rate did not significantly vary the volume fraction of solid $\mathrm{Zn}$-rich and Al-rich phases in $\mathrm{Zn}-5 \mathrm{wt}$ pct $\mathrm{Al}$ alloy during the eutectic solidification. However, the shear rate affected the particle size and the shape factor of solid $\mathrm{Zn}$ and $\mathrm{Al}$ phases in $\mathrm{Zn}-5$ wt pct Al alloy during continuous cooling (Figure 9). The particle sizes decreased slightly with increasing shear rates for both solid Zn-rich and Al-rich phases, even solid Zn-rich phase gave a relatively larger particle size. Meanwhile, the Al-rich phase

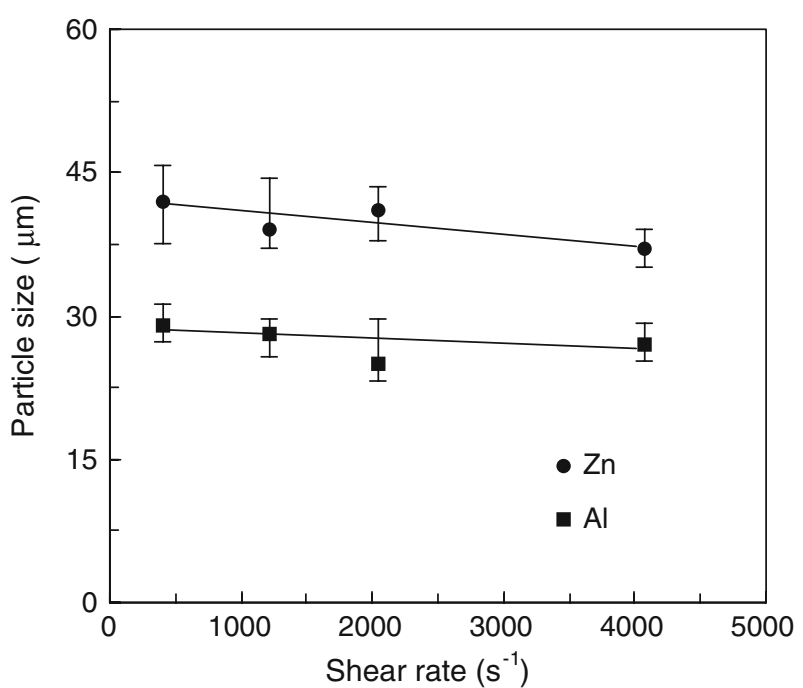

(a)

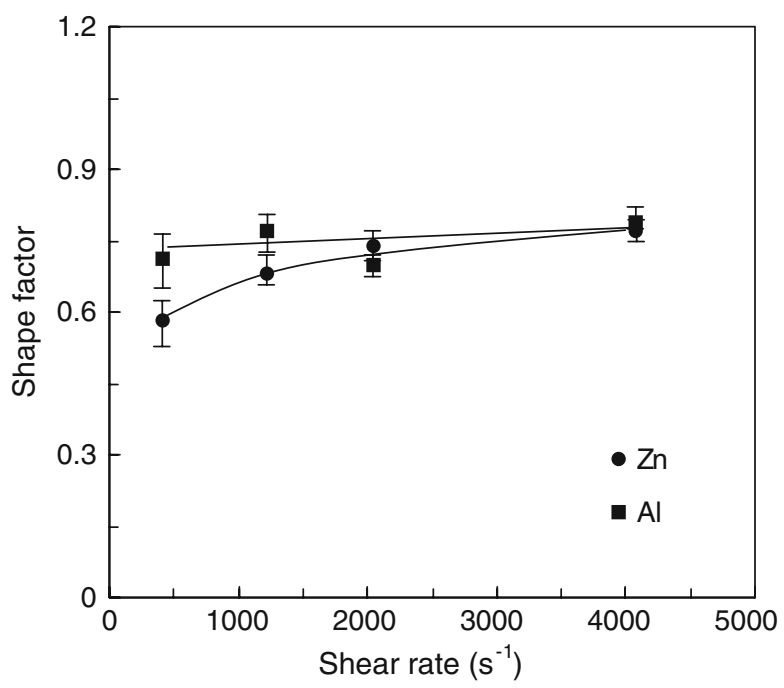

(b)

Fig. 9- (a) Particle size and (b) shape factor of solid $\mathrm{Zn}$ and $\mathrm{Al}$ phases in $\mathrm{Zn}-5 \mathrm{wt}$ pct $\mathrm{Al}$ alloy as a function of shear rate during continuous cooling at $1{ }^{\circ} \mathrm{C} / \mathrm{min}$ from $385^{\circ} \mathrm{C}$ to $380.6^{\circ} \mathrm{C}$, followed by water quenching.

increased slightly, but Zn-rich phase increased significantly in the shape factor with increasing the shear rates in the given experimental ranges. At the lower shear rate of $408 \mathrm{~s}^{-1}$, the shape factors of Al-rich phase and $\mathrm{Zn}$-rich phase were 0.58 and 0.71 , respectively. When the shear rate increased to $4080 \mathrm{~s}^{-1}$, the shape factor increased to 0.79 for Al-rich phase and 0.77 for Zn-rich phase. This implied that the variation of Al-rich phase and Zn-rich phase became insignificant with increasing shear rate.

\section{Microstructure of Near-Eutectic Zn-Al Alloy} Solidified under Intensive Shear

Figure 10 shows the microstructures of $\mathrm{Zn}-6.3 \mathrm{wt}$ pct Al alloy sheared at $4082 \mathrm{~s}^{-1}$ and cooled at $1{ }^{\circ} \mathrm{C} / \mathrm{min}$ from $395^{\circ} \mathrm{C}$ to different temperatures, demonstrating 

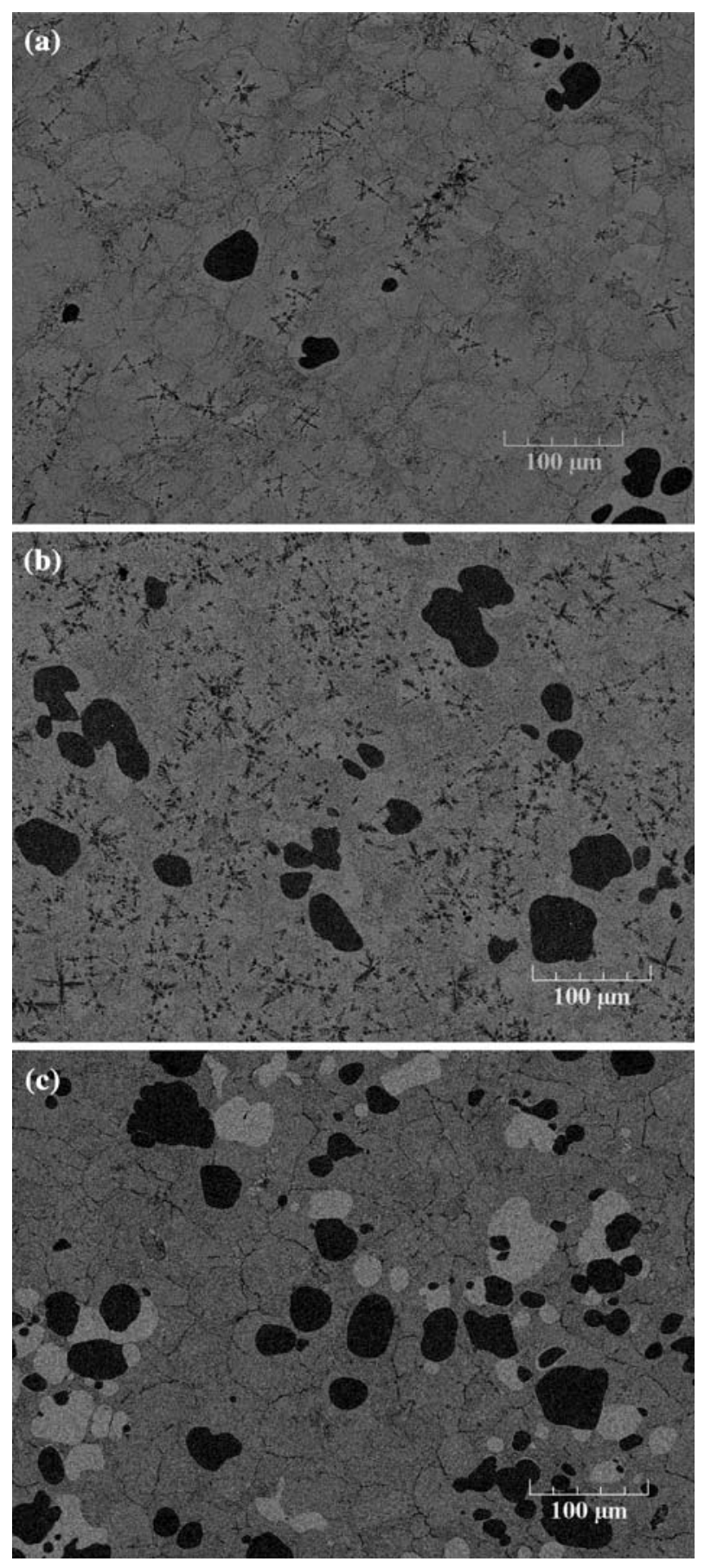

Fig. 10-Backscattered SEM micrographs showing water-quenched microstructures of $\mathrm{Zn}-6.3 \mathrm{wt}$ pct alloy produced under shearing at $4082 \mathrm{~s}^{-1}$ and cooling from $395^{\circ} \mathrm{C}$ at $1{ }^{\circ} \mathrm{C} / \mathrm{min}$ to different temperatures: (a) $391.2{ }^{\circ} \mathrm{C}$, (b) $389.4^{\circ} \mathrm{C}$, and (c) $380.5^{\circ} \mathrm{C}$ (white particles $=\mathrm{Zn}$ phase, and black particles $=\mathrm{Al}$ phase).

the solidification behavior of hypoeutectic $\mathrm{Zn}-\mathrm{Al}$ alloy where $\mathrm{Al}>5 \mathrm{wt}$ pct. Clearly, the primary Al-rich particles emerged at $391.2^{\circ} \mathrm{C}$ with a spherical morphology. The number of Al-rich particles increased with the decrease of shearing temperatures. The $\mathrm{Zn}$-rich particles emerged at $380.5^{\circ} \mathrm{C}$ as a second phase. The appearance of the second solid phase at $380.5^{\circ} \mathrm{C}$ in the semisolid slurry that has contained one solid phase indicates the

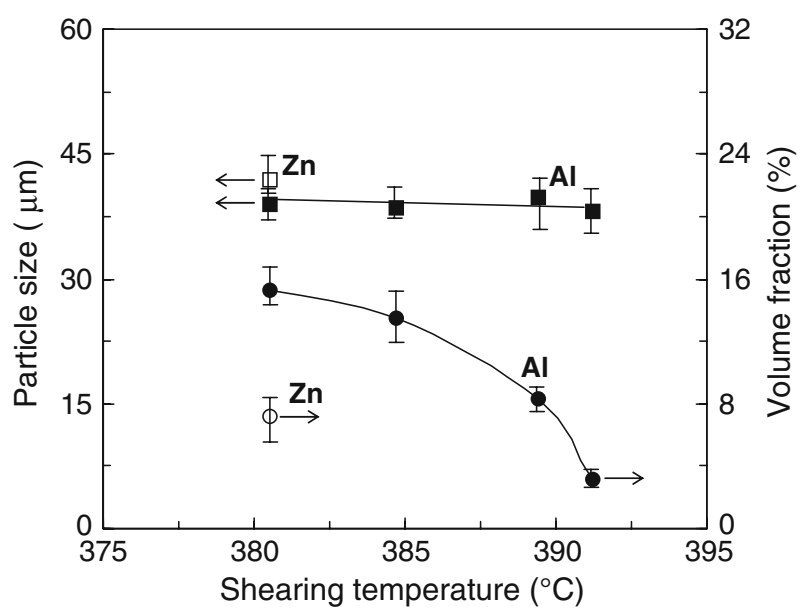

Fig. 11-Effect of shearing temperatures on mean particle size and volume fractions of $\mathrm{Al}$ particle and $\mathrm{Zn}$ particles in $\mathrm{Zn}-.3$ wt pct $\mathrm{Al}$ alloy produced under shearing at $4082 \mathrm{~s}^{-1}$ and cooling at $1{ }^{\circ} \mathrm{C} / \mathrm{min}$ from $395^{\circ} \mathrm{C}$ to different temperatures, followed immediately with water quenching.

occurrence of the eutectic solidification in $\mathrm{Zn}-6.3 \mathrm{wt}$ pct Al alloy under intensive shear. The eutectic reaction should undergo continuously at $380.5^{\circ} \mathrm{C}$ through further heat exchange between melt and barrel, but it was difficult to measure because of the torque limitation in the twin-screw extruder. These results have revealed that the morphology of primary phase and eutectic phases of near-eutectic alloy could be significantly altered during solidification under intensive shear. Another important observation is that only a part of Al-rich particles stuck to the $\mathrm{Zn}$-rich particles during the eutectic solidification, which indicated that the nucleation and growth of the second $\mathrm{Zn}$-rich phase are associated with the existing Al-rich particles. The primary particles formed during the primary solidification under intensive shear have been observed extensively in $\mathrm{Sn}-15$ wt pct $\mathrm{Pb}, \mathrm{Mg}$-alloys, and Al-alloys, which was consistent to the current observation. $^{[15]}$ Figure 11 shows the effect of shearing temperatures on the mean size and the solid fraction of Al-rich and Zn-rich particles in Zn-6.3 wt pet Al alloy sheared at $4082 \mathrm{~s}^{-1}$ and cooled at $1{ }^{\circ} \mathrm{C} / \mathrm{min}$ from $395{ }^{\circ} \mathrm{C}$ to different temperatures. The volume fraction of Al-rich particles increased significantly with the decrease of shearing temperatures. The mean particle sizes were consistent at different shearing temperatures. Meanwhile, the particle sizes and the shape factor at the temperature of the eutectic solidification were rather close for both Al-rich particles $(39.4 \mu \mathrm{m}, 0.74)$ and $\mathrm{Zn}$-rich particles $(41.8 \mu \mathrm{m}, 0.78)$. However, the volume fractions of Al-rich particles were much higher than that of Zn-rich particles at the eutectic solidification, because the existing Al-rich particles had already contributed a volume fraction in the semisolid slurry when Zn-rich phase nucleated at eutectic temperature.

Figure 12 shows the microstructures of $\mathrm{Zn}-4.1 \mathrm{wt}$ pct Al alloy sheared at $4082 \mathrm{~s}^{-1}$ and cooled at $1{ }^{\circ} \mathrm{C} / \mathrm{min}$ from $390{ }^{\circ} \mathrm{C}$ to different temperatures, demonstrating the solidification behavior of hypereutectic $\mathrm{Zn}-\mathrm{Al}$ alloy where $\mathrm{Al}<5 \mathrm{wt}$ pct. The micrographs clearly showed 

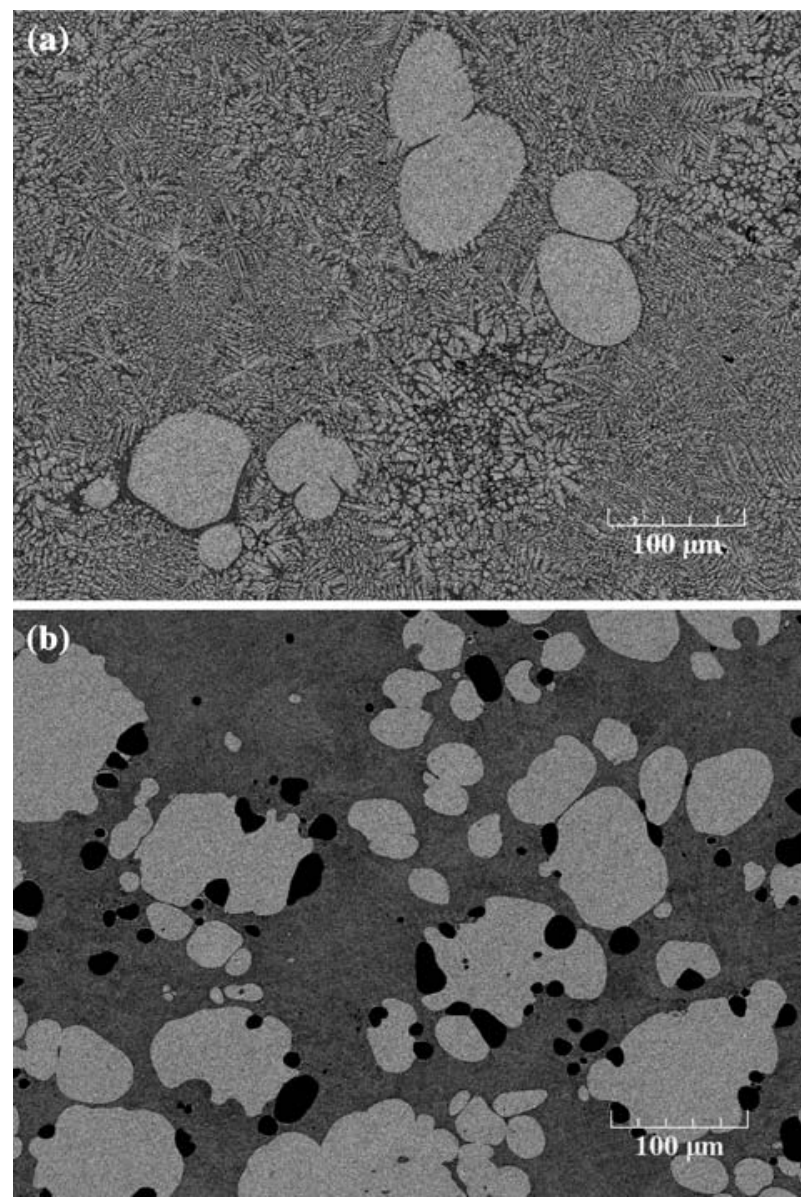

Fig. 12-Backscattered SEM micrographs showing water-quenched microstructures of $\mathrm{Za}-4.1 \mathrm{wt}$ pct $\mathrm{Al}$ alloy produced under shearing at $4082 \mathrm{~s}^{-1}$ and cooling from $390{ }^{\circ} \mathrm{C}$ at $1{ }^{\circ} \mathrm{C} / \mathrm{min}$ to different temperatures: (a) $387.3^{\circ} \mathrm{C}$ and (b) $380.5^{\circ} \mathrm{C}$ (white particles $=\mathrm{Zn}$ phase, and black particles $=\mathrm{Al}$ phase).

that the primary Zn-rich particles were the prior phase during the primary solidification and emerged initially at $387.3^{\circ} \mathrm{C}$ with a spherical morphology. With the decrease of shearing temperature at $380.5^{\circ} \mathrm{C}$, the eutectic solidification occurred to form Al-rich particles at the adjacent of existing $\mathrm{Zn}$-rich particles. The effect of intensive shear on the hypereutectic $\mathrm{Zn}-\mathrm{Al}$ alloy was quite similar to that on the hypoeutectic $\mathrm{Zn}-\mathrm{Al}$ alloy. However, the Zn-rich particles were apparently larger than the Al-rich particles formed during the primary solidification and the eutectic solidification.

Figure 13 shows the effect of shearing temperatures on the mean particle size and the solid fraction of $\mathrm{Zn}$-rich particles and Al-rich particles in $\mathrm{Zn}-4.1 \mathrm{wt}$ pct $\mathrm{Al}$ alloy, sheared at $4082 \mathrm{~s}^{-1}$ and cooled at $1{ }^{\circ} \mathrm{C} / \mathrm{min}$ from $390{ }^{\circ} \mathrm{C}$ to different temperatures. Clearly, the solid fraction of the primary Zn-rich particles increased significantly with the decrease of shearing temperatures. The size of $\mathrm{Zn}$-rich particles was consistent at an order of $75 \mu \mathrm{m}$ at different shearing temperatures in the primary solidification and the eutectic solidification, although there was a slight increase at lower temperatures. At the initial stage of the eutectic solidification, the mean size of the Al-rich particles was $21 \mu \mathrm{m}$, while

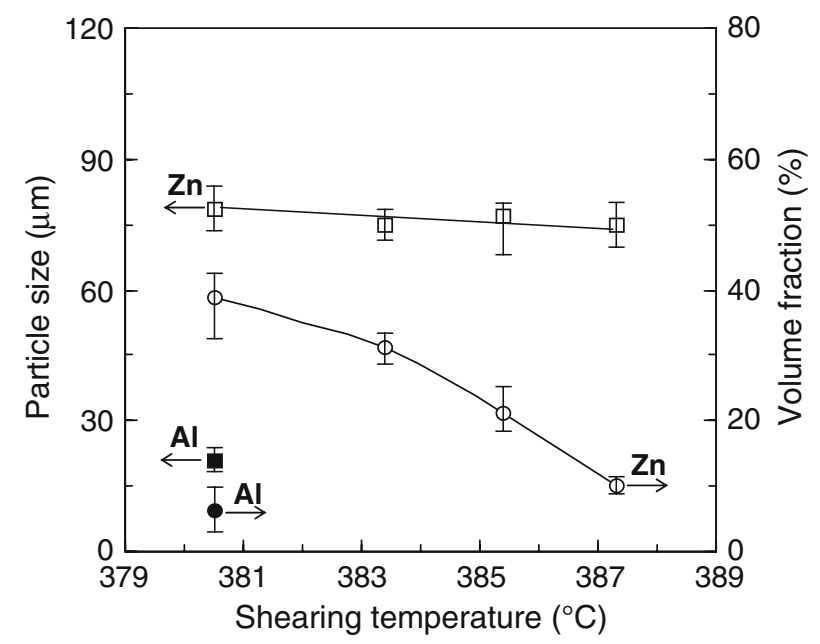

Fig. 13-Effect of shearing temperatures on mean particle size and volume fractions of $\mathrm{Al}$ particle and $\mathrm{Zn}$ particles in $\mathrm{Za}-4.1$ wt pct $\mathrm{Al}$ alloy produced under shearing at $4082 \mathrm{~s}^{-1}$ and cooling at $1^{\circ} \mathrm{C} / \mathrm{min}$ from $390{ }^{\circ} \mathrm{C}$ to different temperatures, followed immediately with water quenching.

the size of the $\mathrm{Zn}$-rich particles was at an order of $75 \mu \mathrm{m}$. For both Al-rich particles and Zn-rich particles formed in the primary solidification and the eutectic solidification, the shape factor was basically no significant variation, and stabilized at the order of 0.75 .

In comparison of Figures 12(b) and 10(c) for the microstructure formed during the eutectic solidification under intensive shear, it should be noted that the $\mathrm{Zn}$-rich particles in the $\mathrm{Zn}-4.1 \mathrm{wt}$ pct $\mathrm{Al}$ alloy were apparently larger than those in the Zn-6.3 wt pet Al alloy. Conversely, the Al-rich particles in the $\mathrm{Zn}-4.1 \mathrm{wt}$ pct Al alloy were apparently smaller than those in the $\mathrm{Zn}-6.3 \mathrm{wt}$ pct $\mathrm{Al}$ alloy. The results also revealed that the temperature of the eutectic solidification was very close for both the $\mathrm{Zn}-4.1$ wt pet $\mathrm{Al}$ alloy and the $\mathrm{Zn}-6.3$ wt pet $\mathrm{Al}$ alloy.

\section{DISCUSSION}

The microstructure and solidification behavior of near-eutectic $\mathrm{Zn}-\mathrm{Al}$ alloys under intensive shear, is observed rather differently than that under conventional solidification. The significant variations include the grain refinement of the eutectic cell when the intensive shear is applied to the alloys described, but close to the liquidus temperature, and the morphology variation of primary and eutectic phases when the intensive shear is applied during solidification. In contrast to the equiaxed dendrites for a primary phase and the lamellae for a eutectic structure in the conventional solidification, the intensive shear promotes the formation of fine and spherical particles for both the primary phase and the eutectic phase. The solidification temperatures are very close to the equilibrium temperatures. This unique behavior can be attributed to the effect of intensive shear on the solidification process of near-eutectic alloys. The effect of intensive shear on the microstructural evolution during the primary solidification of an off-eutectic alloy has been discussed in a previous 
publication. ${ }^{[16]}$ Therefore, the present discussion focuses on the eutectic solidification.

\section{A. Nucleation of Eutectic Alloys under Intensive Shear}

In the liquid state of a binary eutectic alloy, there are two kinds of nuclei existing in the melt and each of them corresponds to one composition. During the conventional eutectic solidification, ${ }^{[17]}$ the nucleation events commence at a temperature below the eutectic temperature, with the heterogeneous nucleation of one of the eutectic phases on nucleants present in the liquid and completed by the heterogeneous nucleation of second eutectic phase on the first. The general belief is that the nucleation process is controlled by the potency, density, and stability of nuclei.

The potency of nucleation is mainly concerned with the interfacial energies. The solid-liquid interfacial energy of the nucleated solid $\left(\sigma_{S L}\right)$ can be considered as the barrier of nucleation, and the solid-liquid interfacial energy of a nucleation catalyst $\left(\sigma_{C L}\right)$ can be considered part of driving force of solidification. In other words, an increase in $\sigma_{C L}$ tends to decrease the wetting angle of the nucleated clusters, and therefore increases the nucleation ability. Conversely, an increase in $\sigma_{S L}$ will tend to increase the wetting angle of the nucleated clusters, and therefore decreases the nucleation ability. Hence, metals that have higher $\sigma_{S L}$ and larger wetting angles are difficult to nucleate and will tend to be good nucleating agents. Metals with lower $\sigma_{S L}$ and low wetting angles will be easier to nucleate and will act as poor nucleating agents. For $\mathrm{Al}-\mathrm{Zn}$ eutectic alloy, according to the calculations, ${ }^{[18,20]}$ the interfacial energy $\sigma_{S L}$ is $0.101 \mathrm{~J} / \mathrm{m}^{2}$ for $\mathrm{Al}$ and $0.127 \mathrm{~J} / \mathrm{m}^{2}$ for $\mathrm{Zn}$. In this point, $\mathrm{Al}$ has better nucleation ability than $\mathrm{Zn}$. On the other hand, it is generally believed that there are a large amount of solidlike clusters in the melt at a temperature near liquidus. These clusters can be nuclei either at the wall of the casting, resulting from the initial thermal undercooling, or in the bulk of the melt, resulting from the constitutional undercooling. However, only a fraction of the clusters can survive and act as nuclei at the initial stage of the conventional solidification, the majority of the nuclei in the bulk melt are remelted because of the temperature fluctuations. In other words, the largest clusters, particularly those with a radius larger than the critical radius for nucleation, are the first to act as nucleation sites, and most of the clusters can be effectively ignored due to their smaller size at the moment of solidification initiation. It is well known that the final microstructure significantly depends on the amount of surviving nuclei during solidification. Therefore, the nucleation event during solidification is not only achieving the size of nuclei for stable growth, but also a rate-determining step.

Under intensive shear, the fluctuations of temperature and composition fields are significantly reduced and become extremely uniform and ever-renewable in each part of the bulk melt. Once the clusters become nuclei, most of them can survive in the uniform temperature field, resulting in an increased density of nuclei. Meanwhile, the intensive shear can produce a better distribution of clusters by dispersing them throughout the melt, which can instantaneously nucleate and grow throughout the whole melt, resulting in an increased effective nucleation rate.

When the intensive shear is applied on the eutectic alloy above but close to the liquidus temperature, the increased nucleation rate can cause a significant grain refinement (Figure 4). However, the following growth procedure still remains the same as that in the conventional solidification due to the absence of intensive shear at this stage, therefore creating lamellar microstructure. When applying intensive shear on the $\mathrm{Zn}-\mathrm{Al}$ eutectic alloy below the liquidus temperature, it is most possibly to disperse the potential nuclei of the Al-rich phase and $\mathrm{Zn}$-rich phase throughout the melt independently and uniformly. The density of Al-rich clusters and Zn-rich clusters in the melt is assumed to be similar. The suppression from one phase to another phase is much less or diminished in the ever-renewed and uniform temperature and composition fields. Therefore, the undercooling for nucleation is minimized and the clusters grow and become nuclei at a temperature close to the equilibrium temperature (Figures 1 and 2).

The nucleation of the second solid phase in the semisolid slurry of near-eutectic Zn-Al alloys that have contained one kind of solid phase is more complicated under intensive shear. The existing solid particles experience an ever-renewed solid/liquid interface in the turbulent flow and the intensive shear to grow in the form of spherical shape. For the eutectic solidification of the semisolid slurry containing Al-rich particles, if the existing Al-rich particles are not in perfect spheroid and the intensity of shear is not sufficiently high, the rejected $\mathrm{Zn}$ cannot immediately dispersed from the solid/liquid interface into the bulk of melt. It therefore accumulates and subsequently nucleates on the imperfect surface of Al-rich particles (Figure 5). If the intensity of shear is sufficiently high and the spherical surface of the existing solid particles is perfect, the rejected $\mathrm{Zn}$ can be immediately dispersed into the bulk of melt to increase the number or the size of $\mathrm{Zn}$ clusters. The separately distributed $\mathrm{Zn}$ clusters can nucleate and grow independently.

\section{B. Growth of Eutectic Alloys under Intensive Shear}

In the conventional eutectic solidification, two phases can grow cooperatively behind an essentially planar solidification front. As the Al-rich $\alpha$ phase solidifies, excess $\mathrm{Zn}$ diffuses a short distance laterally where it is incorporated in the $\mathrm{Zn}$-rich $\beta$ phase. Similarly, the Al atoms, rejected ahead of the $\beta$, diffuse to the tips of the adjacent $\alpha$ lamellae. This diffusion-controlled growth leads to a lamellar morphology in the eventually solidified microstructure of eutectic alloys.

In comparison to the conventional solidification of off-eutectic alloys, where the primary crystal is a single phase of solid, the shear-modified morphologies in eutectic alloys are more complicated. ${ }^{[19]}$ When the eutectic alloy solidifies under a relatively weak shear, investigations ${ }^{[4-12]}$ have confirmed that the morphology still exhibits lamellar structure, with variation on the 


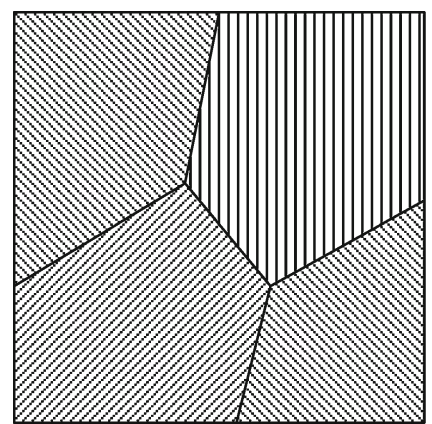

(a)

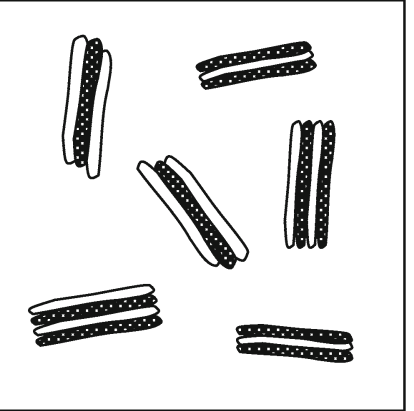

(b)

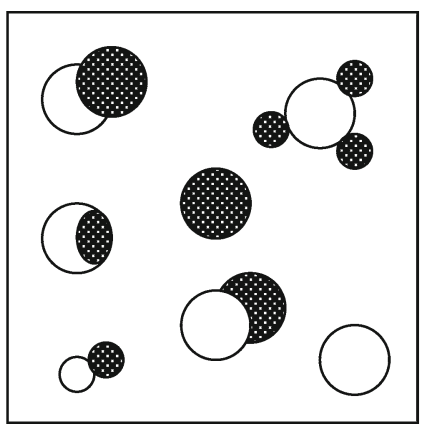

(c)

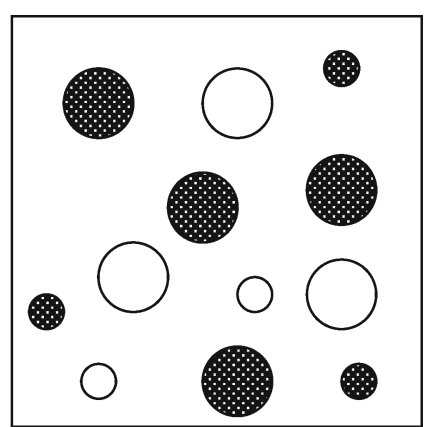

(d)

Fig. 14-Diagram showing effect of forced convection during eutectic solidification on the morphology of eutectic phases in binary alloys: (a) without forced convection, $(b)$ low intensity of forced convection, $(c)$ moderate intensity of forced convection, and $(d)$ high intensity of forced convection.

interlamellar spacing. The origin of the driving force for such variations has been suggested as ${ }^{[20]}$ (1) an asymmetric liquid-solid interfacial energy, (2) solid-solid interfacial asymmetry, (3) a combination of a preferred habit plane with a tendency to anisotropic growth of one or both phases, and (4) deviation of the dendrite growth direction of one or both phases from the overall growth direction of the system. It seems difficult to explain the phenomenon observed in the eutectic solidification under intensive shear because the morphology changes from lamellar structure to fine and spherical particles for both phases.

Recently, the role of intensive shear in primary solidification has been summarized as ${ }^{[16]}$ (1) resulting in very uniform temperature and composition fields in the bulk melt, (2) enhancing heterogeneous nucleation and growth throughout the bulk melt, (3) reducing the thickness of the thermal and solutal diffusion boundary layer at solid/liquid interface, (4) resulting in a significant reduction of constitutional undercooling, and (5) stabilizing the solid/liquid interface. Therefore, the growth of solid particles in the eutectic melt, under intensive shear may be very different due to the enhancement of both thermal and mass transportation and ever-renewed solid/liquid interface.

As mentioned previously, the two eutectic phases in a binary alloy can nucleate subsequently or independently during the eutectic solidification under intensive shear. Accordingly, the following growth procedure can be coupled or independent according to the degree of independence on the intensity of shear. This can be schematically described in Figure 14. When no convection is applied on the melt during the eutectic solidification, it follows the conventional route to form $\alpha+\beta$ lamellar microstructure (Figure 14(a)). When a relatively weak shear is applied on the melt during the eutectic solidification, little perturbation is produced and the enhancement of solute transportation at the solid/liquid interface is limited, which may not totally destroy the lamellar growth. The promotion of solute transportation just varies the interlamellar spacing or the lamellar growth direction in solidification, as observed in previous studies. ${ }^{[4-13]}$ The limited solute transportation at the solid/liquid interface may possibly constrain further growth of solid phase, resulting in the coupled $\alpha$ and $\beta$ in the form of a short and irregular rod microstructure (Figure 14(b)). When the intensity of shear is at a moderate level, the increased solute transportation at the solid/liquid interface and the reduced diffusion layer around solid phase can result in the formation of coupled particles. Two kinds of eutectic phases are alternatively arranged in the coupled particles. In this case, the $\alpha$ phase may form imperfect spherical particles first and subsequently the $\beta$ phase nucleates and grows on the surface of $\alpha$ phase due to the local concentration accumulation. The number of $\beta$ particles coupled on $\alpha$ particles depends on the imperfect points on the surface of the solid $\alpha$ particle, which is further determined by the intensity of shear (Figure 14(c)). Furthermore, if the intensity of shear increases to a sufficiently high level, the temperature and composition fields are extremely uniform throughout the eutectic melt. The solute at the solid/liquid interface is uniformly distributed and the diffusion layer around the solid phase are significantly reduced and maybe diminished.

The nuclei of $\alpha$ and $\beta$ phases are also uniformly distributed throughout the melt. The prior $\alpha$ particles grow and form perfect spheroids with smooth surfaces. The growth velocity and nucleate possibility on the whole surface is equal in the uniform composition field, therefore there is no chance for $\beta$ phase to grow on the surface of the existing $\alpha$ particles. As a result, the $\beta$ phase grows independently from the nuclei in the saturated melt to form perfect spherical particles (Figure 14(d)).

\section{CONCLUSIONS}

1. The nucleation of $\mathrm{Zn}-\mathrm{Al}$ alloys under intensive shear requires small undercooling in both the primary solidification and the eutectic solidification. The eutectic phases can nucleate subsequently or independently throughout the whole melt in the eutectic solidification, depending on the intensity of shear.

2. The intensive shear, applied on the eutectic alloys at a temperature above but close their liquidus, can significantly reduce the size of the eutectic cells but the solidified microstructure still remains the lamellar morphology. 
3. The intensive shear during the eutectic solidification can significantly modify the microstructural morphology of near-eutectic alloys. Both primary phase and eutectic phases exhibit fine and spherical particles. The increased intensity of shear promotes the independence of both solid phases, leading to the uniform and independent distribution of two kinds of particles in the matrix. The second phase can nucleate and grow at the imperfect points of the existing solid particles in a coupled manner at moderate intensity, or nucleate and grow independently from the saturated melt to form perfect spherical particles at extremely high intensity.

\section{ACKNOWLEDGMENT}

The assistance of Dr. Y. Wang, Brunel University, during the experiments is gratefully acknowledged.

\section{REFERENCES}

1. K.A. Jackson and J.D. Hunt: Trans. TMS-AIME, 1966, vol. 236, p. 1129.

2. J.D. Verhoeven and R.H. Homer: Metall. Trans., 1970, vol. 1, pp. 3437-45.
3. D.J. Larson: ASTP Summary Science Report, NASA, Washington, DC, 1976, pp. 449-70.

4. J.M. Quenisset and R. Naslain: J. Cryst. Growth, 1981, vol. 54, p. 465.

5. J.M. Quenisset, R. Sokolowski, and M.E. Glicksman: J. Cryst. Growth, 1983, vol. 63, p. 389.

6. J.Z. Jin, K.F. Kobayashi, and P.H. Shingu: Metall. Trans. A, 1984, vol. 15A, p. 307.

7. M. Li, T. Mori, and H. Iwasaki: Mater. Sci. Eng., 1999, vol. A265, p. 217.

8. N. Apaydin: J. Mater. Sci. Lett., 1982, vol. 1, p. 39.

9. Y.J. Chen and S.H. Davis: Acta Mater., 2001, vol. 49, p. 1363

10. Y.J. Chen and S.H. Davis: Acta Mater., 2002, vol. 50, p. 2269

11. M.C. Flemings: Solidification Processing, McGraw-Hill, New York, NY, 1996, pp. 41-46.

12. S. Ji, Z. Fan, and M. Bevis: Mater. Sci. Eng., 2001, vol. A299, p. 210.

13. C. Rauwendaal: Polymer Extrusion, 3rd ed., Hanser, New York, NY, 1994, pp. 89-97.

14. J.L. Murray: Bull. Alloy Phase Diagrams, 1983, vol. 4, p. 55.

15. L.S. Turng and K.K. Wang: J. Mater. Sci., 1991, vol. 26, p. 2173.

16. S. Ji and Z. Fan: Metall. Mater. Trans. A, 2002, vol. 33A, p. 3511.

17. W. Kurz and D. Fisher: Fundamentals of Solidification, 3rd ed., Trans Tech Publications, Aedermannsdorf, Switzerland, 1989, p. 293.

18. C.J. Smithells: Metal References Book, 6th ed., ASM INTERNATIONAL, Metals Park, OH, 1983, pp. 798-806.

19. S.H. Davis: Handbook of Crystal Growth, D.T.J. Hurle, ed., Elsevier Science Publisher, New York, NY, p. 861.

20. R. Elliott: Eutectic Solidification Processing, Butterworth \& Co Ltd., London, 1983. 